\title{
BMP-7 is an inducer of nephrogenesis, and is also required for eye development and skeletal patterning
}

\author{
Guangbin Luo, ${ }^{1}$ Clementine Hofmann, ${ }^{2,4}$ Antonius L.J.J. Bronckers, ${ }^{1,5}$ Melanie Sohocki, ${ }^{1}$ \\ Allan Bradley, ${ }^{3}$ and Gerard Karsenty ${ }^{1,6}$ \\ ${ }^{1}$ Department of Molecular Genetics, The University of Texas M.D. Anderson Cancer Center, Houston, Texas, 77030 USA; \\ ${ }^{2}$ Department of Biochemistry, ${ }^{3}$ Howard Hughes Medical Institute-Department of Molecular and Human Genetics, Baylor \\ College of Medicine, Houston, Texas, 77030 USA; ${ }^{4} \mathrm{GSF}$, Forschungszentrum für Umwelt und Gesundheit, Institut für \\ Saeugetiergenetik, Oberschleissheim, Germany D-85758
}

Bone morphogenetic proteins (BMPs) are multifunctional growth factors originally identified by their ability to induce ectopic bone formation. To investigate the function of one of the BMPs, BMP-7, we have generated BMP-7-deficient mice using embryonic stem cell technology. BMP-7-deficient mice die shortly after birth because of poor kidney development. Histological analysis of mutant embryos at several stages of development revealed that metanephric mesenchymal cells fail to differentiate, resulting in a virtual absence of glomerulus in newborn kidneys. In situ hybridization analysis showed that the absence of BMP-7 affects the expression of molecular markers of nephrogenesis, such as Pax-2 and Wnt-4 between 12.5 and 14.5 days postcoitum (dpc). This identifies BMP-7 as an inducer of nephrogenesis. In addition, BMP-7-deficient mice have eye defects that appear to originate during lens induction. Finally, BMP-7-deficient mice also have skeletal patterning defects restricted to the rib cage, the skull, and the hindlimbs.

[Key Words: BMP-7; kidney; eye; limb]

Received August 18, 1995; revised version accepted September 29, 1995.

During vertebrate development the permanent kidney is generated by the interaction of two tissue components: the epithelial ureteric bud, and the metanephric mesenchyme (Grobstein 1953, 1955; Saxen 1987). At 11.0 days postcoitum (dpc) the ureteric bud branches out from the Wolffian duct and invades the metanephric mesenchyme. Thereafter, the key event in nephrogenesis is the reciprocal inductive interaction between these two tissues. The metanephric mesenchyme induces the ureteric bud to grow and bifurcate to form the collecting ducts. At the same time, signals from the ureteric bud induce the conversion of metanephric mesenchyme into an epithelial structure. The epithelialization of the metanephric mesenchyme involves several steps. At 11.5 dpc metanephric mesenchyme condenses around the ureteric bud, and condensed mesenchyme segregates into small pretubular aggregates. These aggregates will undergo an epithelialization process to become commashaped bodies, S-shaped bodies, and eventually the epithelial component of the nephron (Saxen 1987).

Classic organ culture experiments have indicated the presence of inducing factors that lead to the condensa-

\footnotetext{
${ }^{5}$ Present address: Department of Oral Cell Biology Academic Center for Dentistry in Amsterdam, Vrijie Universteit van der Boechorstraat, Amsterdam, The Netherlands. ${ }^{6}$ Corresponding author.
}

tion and epithelialization of the metanephric mesenchyme /Gruenwald 1937; Grobstein 1957; Saxen et al. 1976). Metanephric mesenchyme of $11.0 \mathrm{dpc}$ mice cultured in the presence of the ureteric bud, or other inductive tissues such as embryonic spinal cord, proliferates and differentiates into epithelial structures. In contrast, metanephric mesenchymal cells cultured in the absence of other inductive tissues did not proliferate and died. Transfilter induction experiments have led to the postulate that these inductive phenomena could be caused by cell-cell interactions and/or diffusible molecules (Saxen 1987). Wnt- 4 has been identified as one of the molecules necessary for the epithelialization of metanephric mesenchyme. However, in Wnt-4-deficient mice, kidney development is normal until 14.5 dpc (Stark et al. 1994), which suggests that other inducing molecules are important earlier during development.

One molecule that is expressed in the kidney at the time of the earliest induction event is bone morphogenetic protein-7 (BMP-7), also called osteogenic protein-1 (OP-1) (Ozkaynak et al. 1990), a member of the transforming growth factor- $\beta$ (TGF- $\beta$ ) superfamily. Originally, BMPs were purified from bone on the basis of their ability to induce ectopic bone formation when implanted under the skin of rodents (Urist 1965; Sampath and Reddi 1981; Wozney et al. 1988). The skeletal 
morphogenetic function of two members of this family, BMP-5 and growth and differentiation factor 5 (GDF-5), has been documented genetically (Kingsley et al. 1992; Storm et al. 1994). Besides this skeletal patterning function several lines of evidence indicate that the BMPs are morphogenetic molecules for a wide range of tissues during development. First, BMP homologs have been identified in Drosophila, an organism that has no skeleton (Ferguson and Anderson 1992). Second, BMP-4 mediates dorsal/ventral patterning in the early Xenopus embryo (Dale et al. 1992). Third, mouse Bmp-2, Bmp-4, Bmp-6, and $B m p-7$ are expressed early during development, long before the onset of skeletogenesis, and in areas that will not become parts of the skeleton (Lyons et al. 1989, 1990, 1995). Finally, it has been shown that inactivation of $B m p-2$ or Bmp-4 in mice leads to early embryonic lethality, before any skeletal formation has been initiated (Winnier et al. 1995; H. Zhang and A. Bradley, in prep.). Thus, these studies demonstrate that the biological function of the BMPs is not restricted to skeletal patterning during development.

Like many other Bmps, Bmp-7 is expressed in a wide variety of tissues during development (Lyons et al. 1995). $B m p-7$ is expressed in the developing urogenital system at every stage of development, and after birth it is mainly expressed in kidney, suggesting that it may be involved in kidney development. To investigate the function of BMP-7, we have generated BMP-7-deficient mice by embryonic stem (ES) cell technology. We report here that BMP-7 is required in several discrete events involving different organs during development. The most important of these, in terms of penetrance and the effect on the viability of the mouse, is kidney development. BMP-7 is necessary for metanephric mesenchymal condensation after $12.5 \mathrm{dpc}$ and appears to be a survival factor for the metanephric mesenchyme. In the absence of BMP-7, metanephric mesenchymal cells die between 12.5 and $14.5 \mathrm{dpc}$ and, consequently, glomerulus formation ceases after $12.5 \mathrm{dpc}$. The requirement for BMP-7 at the first stage of glomerulus formation indicates that this molecule is an early glomerulus inducer. BMP-7-deficient mice also exhibit other developmental defects in eye development and skeletal patterning with variable penetrance and expressivity. For instance, BMP-7-deficient mice have eye defects that originate at the time of lens formation. Finally, in the absence of BMP-7 the development of the ribs, the skull, and the digits are affected; the absence of BMP-7 leads to polydactyly in hindlimbs.

\section{Results}

\section{Generation of BMP-7-deficient mice}

To generate a null allele of BMP-7, a targeting vector was designed that would generate an allele missing the mature domain of the processed polypeptide by deleting exons 6 and 7. The replacement-type vector pBMP7T has sequences of $6.1 \mathrm{~kb}$ that are homologous with the mouse Bmp-7 locus, a hypoxanthine phosphoribosyl transferase (Hprt) minigene for positive selection and a herpes simplex virus thymidine kinase (HSV tk) cassette for negative selection (Fig. 1A). Recombinant clones were identified by Southern blot hybridization using both $5^{\prime}$ - and $3^{\prime}$-flanking probes, at a frequency of $12 \%$ in the hypoxanthine immunopterin and thymidine (HAT) and FIAU-resistant clones (Fig. 1B). Chimeras were con-
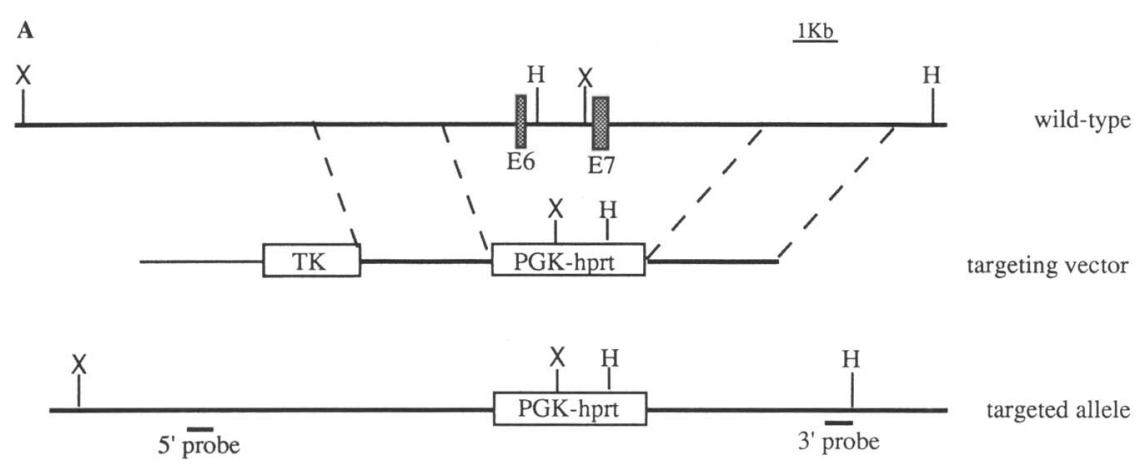

$\begin{array}{ccc}13.0 \mathrm{~kb} \mathrm{Xba} \mathrm{I} & 9.2 \mathrm{~kb} \text { Hind III } & \text { wild-type } \\ 10.9 \mathrm{~kb} \mathrm{Xba} \mathrm{I} & 5.6 \mathrm{~kb} \text { Hind III } & \text { mutant }\end{array}$

B

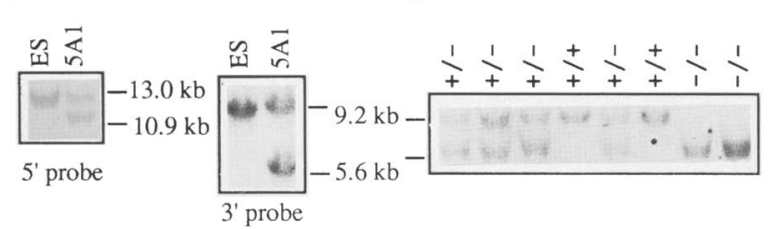

Figure 1. Gene targeting at the $B m p-7$ locus. (A) Schematic representation of the expected gene replacement at the mouse Bmp-7 locus. Exons 6 (E6) and 7 (E7), coding for six of the seven cysteine residues of the mature BMP-7, are represented as dark, stippled boxes. The 5' and 3' external probes used for Southern blot analysis are shown as solid bars, and the diagnostic fragments as lines. (X) Xbal; (H) HindIII. (B) Southern blot analysis of the putative targeted clone $5 \mathrm{~A} 1$. Both $5^{\prime}$ and $3^{\prime}$ external probes detected predicted restriction fragments. (C) Southern blot analysis of neonates from intercrosses between heterozygous BMP-7 mutant mice. $1+1+1$ Wild-type mutants; $1+1-\mid$ heterozygoous mutants; $(-1-)$ homozygous mutants. (D) Northern blot analysis of total RNA from 12.5-dpc embryos from a heterozygous intercross, using as a probe the $3^{\prime}$ untranslated region of the mouse $B m p-7$ cDNA. The two Bmp-7 transcripts, 4.0 and $2.0 \mathrm{~kb}$, are indicated. A glyceraldehyde phosphatase (GADPH) cDNA probe was used as an internal control for the amount of RNA loaded in each lane. 
structed by injecting targeted ES cells into C57BL/ 6 blastocysts. Chimeric males were crossed with $\mathrm{C} 57 \mathrm{BL} / 6 \mathrm{fe}$ males to transmit the mutant allele $\left(b m p-7^{m 1}\right)$ through the germ line (Fig. 1C). Chimeras generated from one targeted clone transmitted the mutation through the germ line. Northern blot analysis performed with RNA samples from 12.5-dpc embryos failed to detect any BMP-7 mRNA in bmp- $7^{m 1} / b m p-7^{m 1}$ homozygotes (Fig. 1D). Likewise, immunohistochemistry performed on kidney sections of newborn mice using a monoclonal antibody against the mature domain of BMP-7 (Vukicevic et al. 1994) could not detect any BMP-7 protein in the kidneys of mutant mice (data not shown).

\section{Morphological phenotypes of BMP-7-deficient mice}

Heterozygous $\left(b m p-7^{m 1} /^{+}\right)$mice were phenotypically normal. Crosses between these heterozygotes produced litters of normal size, although about one-quarter of the neonates had distinctive morphological features. Grossly, they were all smaller in size (body weight, $85 \%$ of normal), $82 \%$ exhibited polydactyly in the hindlimbs, and $71 \%$ had either anophtalmia or microphtalmia (Table 1). All of the morphologically abnormal mice died within $48 \mathrm{hr}$ after birth. Southern blot hybridization analysis revealed that all of these abnormal mice were $b m p-7^{m 1} / b m p-7^{m 1}$ homozygotes and that they were recovered at the expected Mendelian ratio $(0.005<P$ $<0.01$ ), indicating that all $b m p-7^{m 1} / b m p-7^{m 1}$ mice survived to term. The morphological appearance of bmp$7^{m 1} / \mathrm{bmp}-7^{m 1}$, as well as the penetrance and severity of the three phenotypes described below, were identical on a C57BL/6×129/Sv genetic background and on a 129/Sv background. The results described in this study were obtained by analyzing mutant mice on a hybrid genetic background.

\section{BMP-7 is required for normal kidney development}

To identify the cause of death in $b m p-7^{m 1} / b m p-7^{m 1}$ mice, autopsies were performed on newborn animals. All of the $b m p-7^{m 1} / b m p-7^{m 1}$ mice had small dysgenic kidneys with hydroureters (Table 1). Histological analysis showed that these abnormal kidneys have severely dilated collecting ducts separated by large areas of stromal cells and extracellular matrix (Fig. 2G,H). These dysgenic kidneys always had $<3$ glomeruli per histological section compared with $>100$ in the section of control wild-type kidneys. The dysgenic $b m p-7^{m 1} / b m p-7^{m 1}$ kidneys do not have an identifiable metanephric mesenchyme, and there was no evidence of glomerulus forma- tion in the cortical region (Fig. $2 \mathrm{H}$ ), whereas in the wildtype control, active glomerulogenesis is evident (Fig. 2G). These observations indicate that BMP-7 plays a critical role during nephrogenesis. We did not detect any abnormalities in other parts of the urogenital system or in any other internal organs of the $b m p-7^{m 1} / b m p-7^{m 1}$ mice.

To determine the embryological basis of this abnormality, the kidneys of wild-type and mutant embryos were examined at different times during development. In the normal 12.0-dpc embryos, the distal part of the ureteric bud has branched several times and the buds are surrounded by condensed mesenchymal cells. At that stage, the kidney rudiments of mutant embryos are smaller than those of wild-type embryos but are otherwise histologically indistinguishable (Fig. 2A,B). Just half a day later, the metanephric rudiment is recognizably different between the $b m p-7^{m 1} / b m p-7^{m 1}$ and wild-type embryos. In the 12.5-dpc wild-type kidney, noninduced metanephric mesenchyme is present at the periphery (cortical region), and condensed mesenchymal cells surround every ureteric bud. Part of the condensed mesenchymal cells have already fractionated to form pretubular aggregates. In the $b m p-7^{m 1} / b m p-7^{m 1}$ kidneys $(n=8)$, noninduced mesenchymal cells are also present in the cortical region, but the condensed mesenchymal cells that should surround the ureteric buds are either partially or totally absent. A few pretubular aggregates are observed (Fig. 2C,D). In the 14.5-dpc wild-type kidney noninduced metanephric mesenchyme is present in the cortical region, ureteric buds are invariably surrounded by condensed mesenchymal cells, and pretubular aggregates are present (Fig. 2E). Some of these aggregates have already developed into comma-shaped bodies, S-shaped bodies, and mature glomeruli. In contrast, $b m p-7^{m 1}$ bmp- $7^{m 1}$ kidneys at $14.5 \mathrm{dpc}(n=6)$ have a reduced number of noninduced mesenchymal cells in the cortical region. Condensed mesenchymal cells and pretubular aggregates are completely absent, and very few commashaped bodies, S-shaped bodies, and maturing glomeruli could be observed (Fig. 2F). Thus, in the absence of BMP7 , the process of glomerulus formation was recognizably impaired at $12.5 \mathrm{dpc}$, and at $14.5 \mathrm{dpc}$ virtually no mesenchymal derivatives were present.

To determine whether the phenotype coincided with the pattern of Bmp-7 expression during urogenital development, we performed in situ hybridization experiments. At 9.5 dpc, Bmp-7 is expressed in the Wolffian ducts, which give rise to the ureteric buds (Lyons et al. 1995; data not shown). At $12.5 \mathrm{dpc}, B \mathrm{mp}-7$ is expressed predominantly in the ureteric bud epithelium and, to a

Table 1. Morphological analysis of neonatal mutant mice

\begin{tabular}{lcccc}
\hline Phenotype & Dysgenic kidneys & $\begin{array}{l}\text { Anophtalmia and/or } \\
\text { microphtalmia }\end{array}$ & \multicolumn{2}{c}{ Extra digit } \\
\cline { 4 - 5 } Number of abnormal/number examined & $17 / 17$ & $12 / 17$ & $14 / 17$ & in forelimbs \\
\hline
\end{tabular}



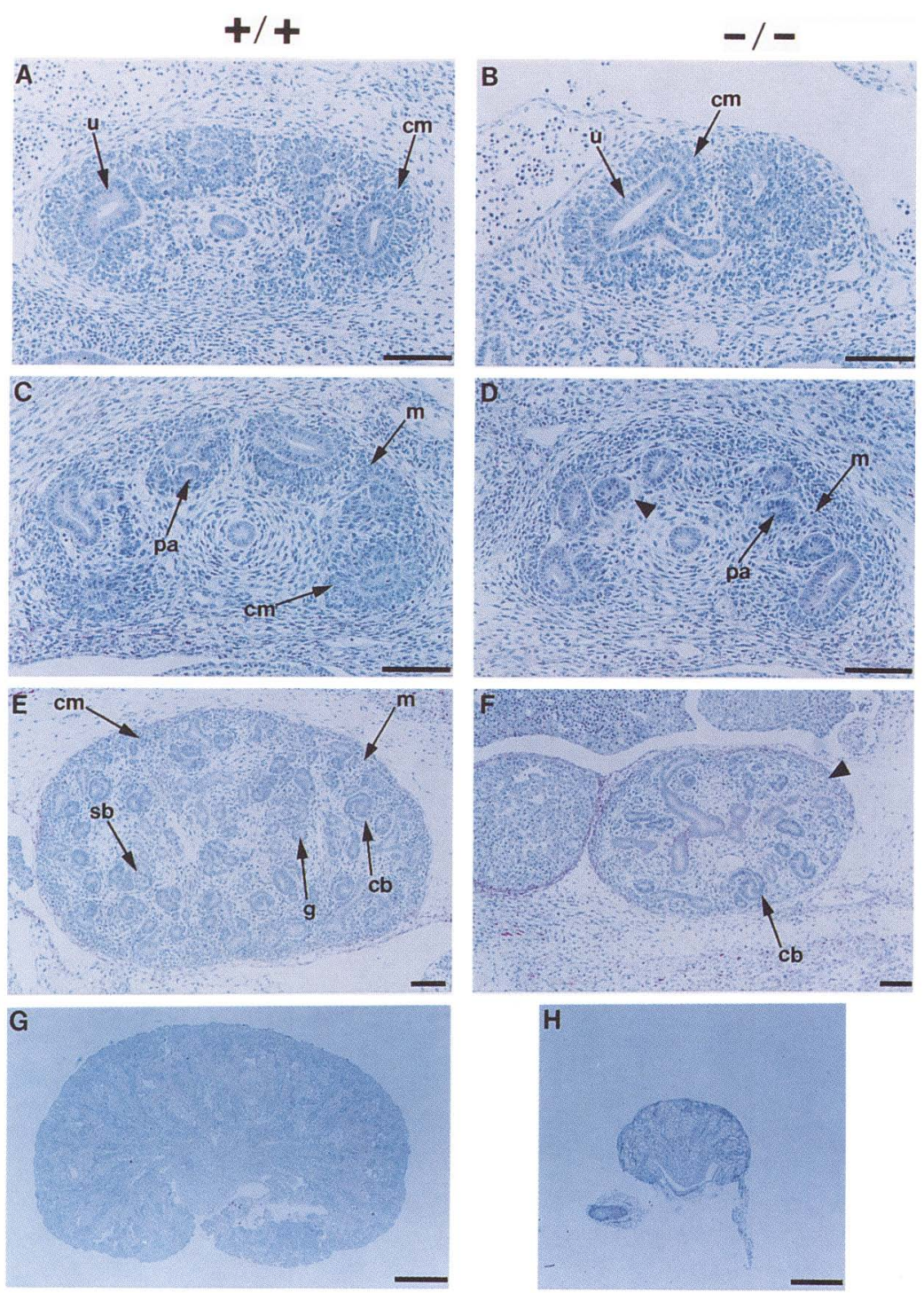

Figure 2. Histological analysis of kidney development in BMP-7-deficient mice. Shown are sagittal sections of kidney of 12.0-dpc $(A, B), 12.5$ dpc $|C, D|, 14.5-\mathrm{dpc}(E, F)$ embryos, and newborn mice $(G, H)$. At $12.0 \mathrm{dpc}$, the mutant kidney is smaller than the control $(A, B)$; both the ureteric bud $(u)$ and the condensed mesenchymal cells $(\mathrm{cm})$ are present in the mutant kidney $(B)$. At 12.5 $\mathrm{dpc}$, there is a severe reduction in mesenchymal condensation in the mutant kidney (arrowhead in $D$ ) compared with the control $(\mathrm{cm}$ in $C)$; pretubular aggregates (pa) are present in both the mutant and the wild type $(C, D)$. At $14.5 \mathrm{dpc}$, the mutant kidney $(F)$ is clearly smaller than the wild type $(E)$. There is no mesenchymal condensation in the mutant kidney. There is also a reduction in the number of noninduced mesenchymal cells (arrowhead in F). (g) Glomerulus; (cb) commashaped body; (sb) S-shaped body. At the neonatal stage, the mutant kidney is much smaller than the wild type. In addition, there is an absence of mesenchymal cells and glomerogenesis in the mutant kidney $(G, H) .(A-F)$ Bar, $100 \mu \mathrm{m} ;(G, H)$ bar, $500 \mu \mathrm{m}\langle G, H\rangle$. lesser extent, in the surrounding condensed mesenchymal cells (Fig. 3A). At $14.5 \mathrm{dpc}, B \mathrm{mp}-7$ transcripts are present in the same structures, and also in pretubular aggregates, but are absent in the comma-shaped and $\mathrm{S}$-shaped bodies. In the glomeruli, Bmp-7 transcripts were detected in the podocytes (Fig. 3B). Bmp-7 is also expressed in the spinal cord (data not shown), a tissue that can replace ureteric bud to induce metanephric mesenchyme differentiation in vitro (Saxen 1987).

To characterize the kidney phenotype in more detail, we examined the patterns of expression of several wellcharacterized molecular markers of either metanephric mesenchyme or kidney epithelial cells at 12.5 and 14.5 dpc. The Wilms' tumor gene WT1 (Call et al. 1990) encodes a transcription factor essential for kidney development (Kreidberg et al. 1993). WT1 is expressed in the metanephric mesenchymal cells at $12.5 \mathrm{dpc}$ and in podocytes of the mature glomeruli starting at $14.5 \mathrm{dpc}$ (Armstrong et al. 1992). In 12.5-dpc bmp- $7^{m 1} / b m p-7^{m 1}$ kidneys, WT1 was expressed in the mesenchymal cells (Fig. 3B). The presence of WT1 transcripts in the developing kidney of a 12.5 -dpc $b m p-7^{m 1} / b m p-7^{m 1}$ embryo is consistent with the histological analysis showing the presence of mesenchymal cells at this stage. At $14.5 \mathrm{dpc}$, in the $b m p-7^{m 1} / b m p-7^{m 1}$ kidneys, WT1 transcripts were present in the podocytes of the few glomeruli but were greatly reduced in the cortical region where the noninduced metanephric mesenchyme should be. WT1 transcripts were also completely absent around the ureteric buds where the condensed mesenchymal cells should be present (Fig. 3F). The absence of WT1 expression in the cortical region of $14.5-\mathrm{dpc} b m p-7^{m 1} / b m p-7^{m 1}$ embryo, where both the noninduced mesenchyme and the condensed mesenchymal cells should be present, is consistent with the histological observations that very few noncondensed mesenchymal cells are present in the mutant kidney at this stage of development. In addition, the fact that WT1 expression is detected in the few glomeruli 


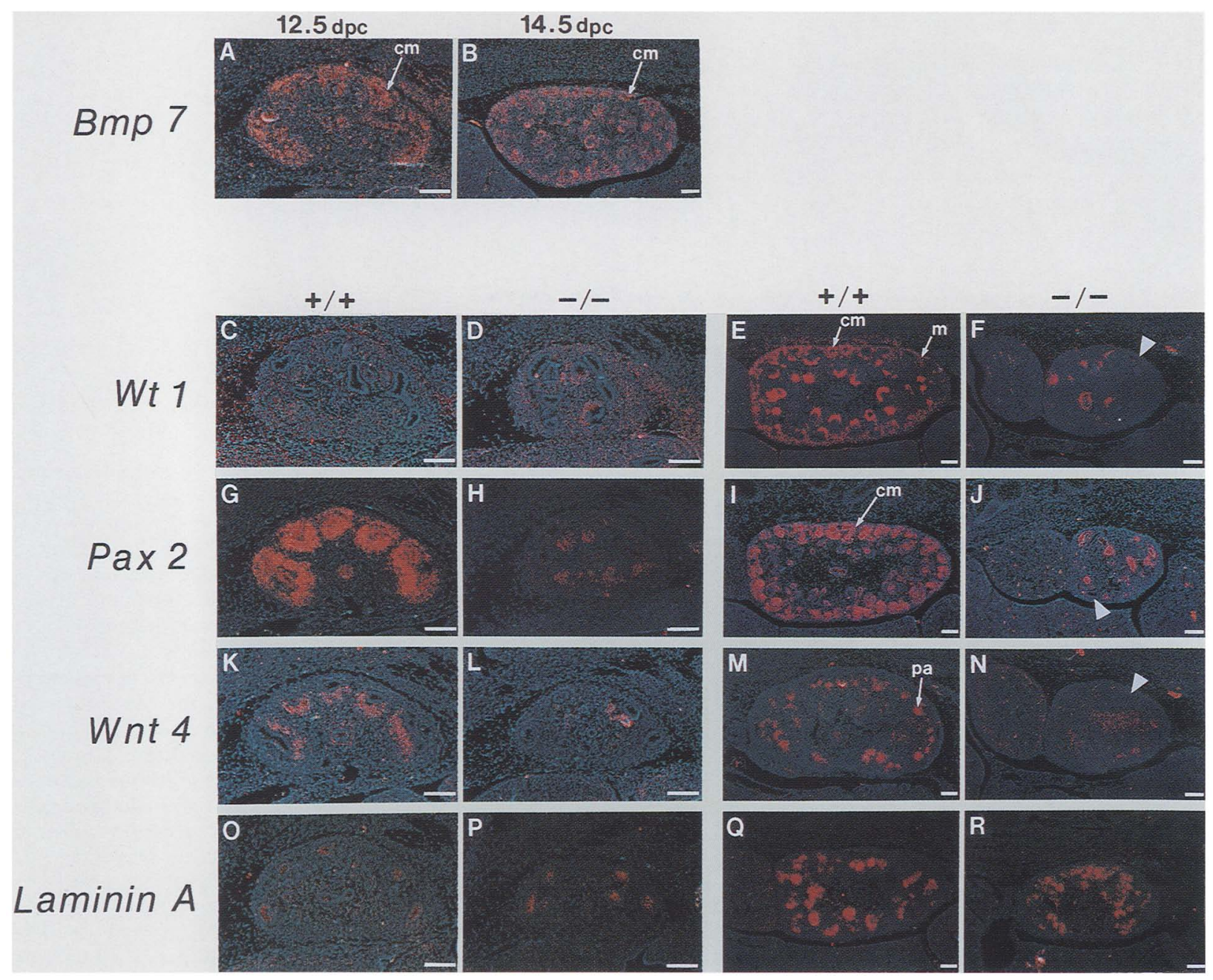

Figure 3. Expression of kidney marker genes in 12.5-dpc and 14.5-dpc wild-type and mutant kidneys. $(A, B) B m p-7$ expression during normal kidney development. At $12.5 \mathrm{dpc}, B \mathrm{mp}-7$ is expressed in the ureteric buds and the condensed mesenchymal cells (cm) around them $(A)$. At $14.5 \mathrm{dpc}$, its expression is extended further to the pretubular aggregates and the glomeruli at high levels, but is down-regulated in the comma- and S-shaped bodies $(B) .(C-F) W T 1$ expression in wild-type $(+1+)$ and mutant $|-1-|$ kidneys. At 12.5 $\mathrm{dpc}$, WT1 is expressed in the kidney noninduced mesenchyme of both the wild-type $(C)$ and the mutant $(D)$. At $14.5 \mathrm{dpc}$, WT1 transcripts that are detected in the noninduced mesenchyme $(\mathrm{m})$ and the condensed mesenchymal cells $(\mathrm{cm})$ in the cortical region of the wild-type kidney $(E)$ but are no longer present in the same region of the mutant kidney (arrowhead in $F)$. $(G-J) P a x-2$ expression in wild-type and mutant kidneys. At $12.5 \mathrm{dpc}$, Pax-2 is expressed in the condensed mesenchymal cells and pretubular aggregates in both the wild type $(G)$ and the mutant $(H)$. Note that the level of expression in the condensed mesenchymal cells of the mutant kidney is much lower compared with that in the wild-type kidney. At $14.5 \mathrm{dpc}, \mathrm{Pax}-2$ is expressed in condensed mesenchymal cells and pretubular agreggates in the wild-type kidney $(I)$. At the same stage in the mutant kidney, Pax-2 expression can only be detected in the ureteric buds but not in the areas adjacent to the ureteric buds where condensed mesenchymal cells and pretubular aggregates should be present in normal kidney (arrowhead in $J$ ). $(K-N)$ Wnt-4 expression in wild-type and mutant kidneys. At 12.5 dpc, Wnt -4 is expressed in pretubular aggregates $(K)$. In the mutant kidney, Wnt-4 expression is barely detectable in areas adjacent to only some of the ureteric buds $(L)$. At $14.5 \mathrm{dpc}$, Wnt- 4 is expressed in pretubular aggregates and the collecting duct system $(M)$. In the mutant kidney, Wnt-4 expression is absent from the areas adjacent to the ureteric buds in the cortical region (arrowhead in $N)$. (O-R) Laminin $A$ expression in wild-type and mutant kidneys. At $12.5 \mathrm{dpc}$, Laminin $A$ is expressed in the ureteric buds of both the wild-type $(O)$ and the mutant $(P)$ kidneys. At $14.5 \mathrm{dpc}$, Laminin $A$ expression in the ureteric buds can be detected in both the wild type and the mutant, whereas its expression in the epithelialized comma-shaped bodies, detectable in the wild type (Q), is absent from the mutant kidney (R). Bars, $100 \mu \mathrm{m}$.

that are formed indicates that the absence of WT1 expression in the mutant kidney is not a direct consequence of the absence of BMP-7 but simply reflects the absence of the appropriate cell type (i.e., the metanephric mesenchyme).
Pax-2 encodes a member of the Pax family of transcription factors. In vitro, Pax-2 regulates the epithelial conversion of the metanephric mesenchyme (Dressler et al. 1993). At $12.5 \mathrm{dpc}$, in the developing kidney of normal embryo, Pax-2 is expressed in the ureteric bud, the sur- 
rounding condensed mesenchymal cells, and, at a higher level, in the pretubular aggregates. At this stage, in the $b m p-7^{m 1} / b m p-7^{m 1}$ kidneys, Pax-2 is expressed in the same structures as in the wild-type control but at a reduced level (Fig. 3G,H). At $14.5 \mathrm{dpc}$, in wild-type embryos, Pax-2 continues to be expressed at moderate levels in ureteric buds and condensed mesenchymal cells, and at a higher level in pretubular aggregates and the comma-shaped bodies (Fig. 3I). In the $b m p-7^{m 1} / b m p-7^{m 1}$ kidneys, Pax-2 expression in the cells surrounding the ureteric buds is virtually absent, but its expression in ureteric buds appears to be unaffected (Fig. 3J). The reduction of $P a x-2$ expression in the 12.5-dpc $b m p-7^{m 1}$ / $b m p-7^{m 1}$ kidney is consistent with the result of histological analysis showing that there were less mesenchymal condensations at this stage. The complete absence of Pax-2 expression in the cortical region of the 14.5-dpc $b m p-7^{m 1} / b m p-7^{m 1}$ kidney is also consistent with the reduced number of noninduced mesenchymal cells at this stage.

Wnt-4, a member of the Wnt family of growth factors (Parr and McMahon 1994), is expressed in the ureteric bud and in pretubular aggregates (Fig. 3I, $\mathrm{K}_{\text {; }}$ Stark et al. 1994). At 12.5 dpc in the kidney of normal embryo, Wnt-4 expression was detected in the pretubular aggregates adjacent to every ureteric bud (Fig. 3K). At the same stage in the mutant embryo, Wnt-4 expression was barely detectable in pretubular aggregates (Fig. $3 \mathrm{~L}$ ). At $14.5 \mathrm{dpc}$ in the kidney of normal embryo, Wnt-4 was expressed in pretubular aggregates (Fig. $3 \mathrm{M}$ ). At this stage in the mutant kidney Wnt-4 expression is completely absent (Fig. 3N), which is consistent with the absence of pretubular aggregates distinguishable histologically. The clear reduction of Wnt-4 expression observed in the kidney of $12.5-\mathrm{dpc} b \mathrm{mp}-7^{\mathrm{m} 1} / \mathrm{bmp}-7^{m 1} \mathrm{em}$ bryos suggests either that the pretubular aggregates are intrinsically abnormal in the mutant kidney or that Wnt-4 expression in the pretubular aggregates is regulated by BMP-7.

To study ureteric bud development in bmp- $7^{m 1} / b m p$ $7^{m 1}$ mice, we examined the expression of Laminin $A$, a marker of the epithelial cells of ureteric buds and the collecting ducts (Klein et al. 1990). Laminin A expression in the ureteric buds of $b m p-7^{m 1} / b m p-7^{m 1}$ kidneys was unchanged compared with that in the wild-type kidney at both 12.5- and 14.5-dpc embryos (Fig. 3O,P,Q,R). Thus, the absence of BMP-7 did not affect ureteric epithelium development, which is consistent with the result of histological analysis. At $14.5 \mathrm{dpc}$, Laminin $A$ is also highly expressed in the comma-shaped bodies that are undergoing mesenchymal to epithelial transition. In $b m p-7^{m 1} / b m p-7^{m 1}$ kidneys, Laminin $A$ expression in comma-shaped bodies was not observed (Fig. 3R), consistent with the lack of comma-shape bodies in 14.5-dpc bmp $-7^{m 1} / b m p-7^{m 1}$ kidneys.

In summary, the in situ hybridization analysis indicates that the absence of BMP-7 affects the expression of molecular markers specific for the metanephric mesenchyme as early as $12.5 \mathrm{dpc}$, but not the expression of the molecular marker of epithelial cells. This result is in agreement with our histological analysis and raises the hypothesis that absence of BMP-7 leads to programmed cell death $\langle\mathrm{PCD}\rangle$ of metanephric mesenchymal cells early during nephrogenesis.

During normal kidney development, PCD is normally restricted to stromal cells (Koseki et al. 1992). Analysis of sections of the $b m p-7^{m 1} / b m p-7^{m 1}$ kidneys by the TUNEL assay showed PCD in stromal cells, but also in the noninduced metanephric mesenchyme. PCD was detectable in metanephric mesenchyme in the three stages examined: $12.0 \mathrm{dpc}(n=4$; data not shown), $13.5 \mathrm{dpc}$ ( $n=4$; Fig. 4), and $14.5 \mathrm{dpc}(n=4$; data not shown). These results suggest that BMP-7 may act as a survival factor for metanephric mesenchymal cells and that the absence of expression of molecular markers of mesenchymal cells may be a consequence of the death of mesenchymal cells.

\section{BMP-7 is involved in eye development}

bmp $-7^{m 1} / b m p-7^{m 1}$ mice are born with unilateral or bilateral eye defects (Table 1). These are variable in expressivity, ranging from an absence of eye structures to eyes
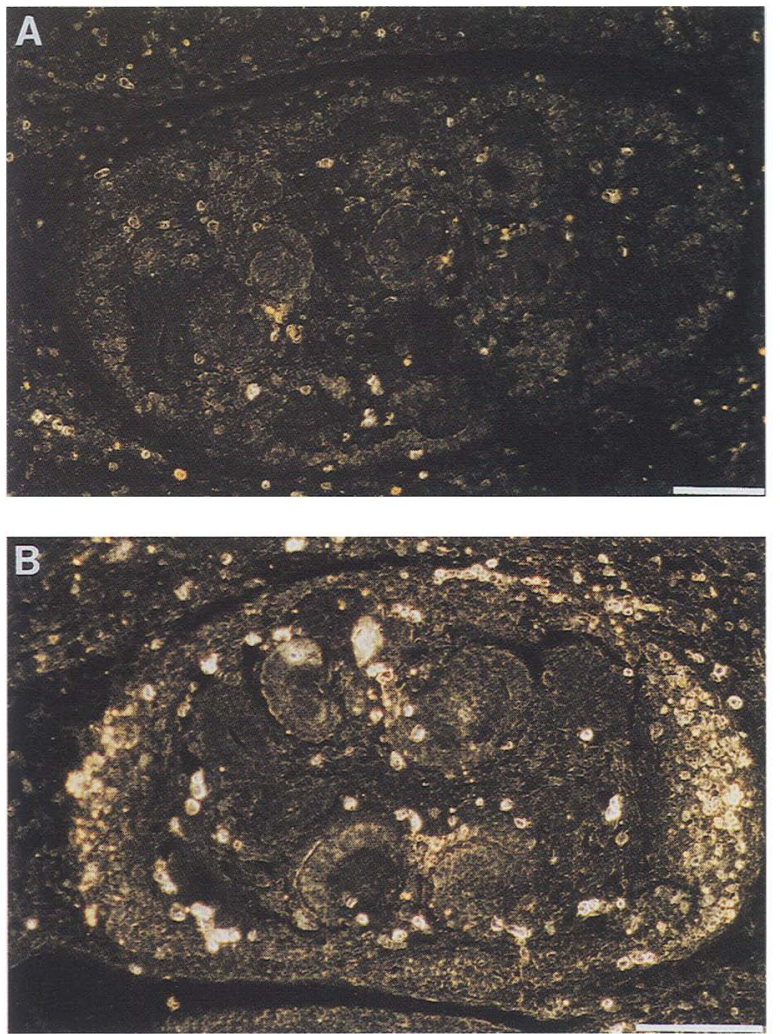

Figure 4. In situ detection of apoptosis in developing wild-type and mutant kidneys. Section of wild-type 13.5-dpc embryos $(A)$ or $b m p-7^{m 1} / b m p-7^{m 1}$ embryos $(B)$ was analyzed by the TUNEL assay, as described in Materials and methods, and by dark-field microscopy. Representative sections are shown. Note the apoptosis in the cortical region of the mutant kidney where the metanephric mesenchymal cells are located. Bars, $100 \mu \mathrm{m}$. 
of normal size. Four $b m p-7^{m 1} / b m p-7^{m 1}$ mice lacking identifiable eyes were examined histologically. In these mice, the lens, retina, and cornea were absent (Fig. 5B). In other $b m p-7^{m 1} / b m p-7^{m 1}$ mutant mice, the cornea, lens, and retina were well developed (data not shown). Eye development was examined during embryogenesis to establish the cause of the eye phenotype. At $11.0 \mathrm{dpc}$, when the optic cup has developed and invagination of the lens vesicle is visible in wild-type embryos (Pei and Rhodin 1970; Kaufman 1992), the optic cups and lens vesicles have not developed unilaterally $(21 \%)$ or bilaterally $(14 \%)$ in $b m p-7^{m 1} / b m p-7^{m 1}$ embryos $(n=20)$. In the remaining mutant embryos $(65 \%)$, optic cups were present and lens formation had occurred; however, lens vesicles were smaller than those of wild-type embryos at the same stage (data not shown). We also examined eye development in 10.5-dpc $b m p-7^{m 1} / b m p-7^{m 1}$ embryos and found that in one of the mutant embryos, one eye

Figure 5. Analysis of the eye phenotype of BMP-7-deficient mice. $(A-G)$ Histological analysis of eye development. $(A)$ Frontal sections of the head of a newborn wild-type mouse with well-developed cornea $(\mathrm{c})$, retina $(\mathrm{r})$, lens $(\mathrm{le})$, and lacrimal glands $(\mathrm{lg})$. (B) Frontal section of the head through the vicinity of the eye of a BMP-7-deficient newborn mouse showing the absence of any identifiable eye structure except the lacrimal glands. $(C-$ $G)$ Frontal sections of the head of 10.5 dpc embryos. $(C)$ Eyes of a wild-type embryo with well-developed optic cup and lens vesicle. (D) Frontal section of the head of a mutant littermate. Note that on one side, the optic cup has developed and the lens vesicle is present, whereas on the other side the optic cup is rudimental and the lens vesicle is absent (arrowhead). $(E-G)$ Higher magnification of one eye of the wild-type embryo $\langle E|$, the right eye of the mutant embryo $(F)$, and the left eye of the mutant embryo, which has no identifiable lens vesicle $(G)$. $(H, I)$ Pax -6 expression in the eyes of 12.5-dpc wild-type $(H)$ and mutant $(I)$ embryos. In both the wild type and the mutant, Pax-6 is expressed in the optic cup and the lens vesicle. Note that the eye structure of the mutant is much smaller than that of the wild type. In addition, the eye development process was delayed, leaving the lens vesicle connected with the surface ectoderm. $(A, B)$ Bar, $500 \mu \mathrm{m} ;(C, D)$ bar, $200 \mu \mathrm{m}$; bar, $(E-I)$ bar, $100 \mu \mathrm{m}$. had developed normally whereas the other eye remained rudimentary with no optic cup formation and no lens vesicle invagination (Fig. 5C-G). We did not observe any consistent phenotypic abnormalities in younger bmp$7^{m 1} / b m p-7^{m 1}$ embryos (data not shown). This phenotype is coincident with the expression of $B m p-7$ during eye development. Bmp-7 transcripts are present in the optic vesicle and the surrounding head ectoderm as early as 9.5 dpc (Lyons et al. 1995; data not shown). To gain insight into this eye defect, expression of Pax-6 was examined in the developing eye of $b m p-7^{m 1} / b m p-7^{m 1}$ embryos. Pax -6 is essential for the earliest events of eye development in both flies and vertebrates and continues to be expressed in the retina and the lens of the 12.5-dpc mouse embryo (Hogan et al. 1988; Grindley et al. 1995; Halder et al. 1995). In a subset of bmp- $7^{m 1} / \mathrm{bmp}-7^{m 1}$ embryos that had eyes at $12.5 \mathrm{dpc}$, Pax-6 expression was indistinguishable from that in wild-type embryos (Fig. 5E,F).
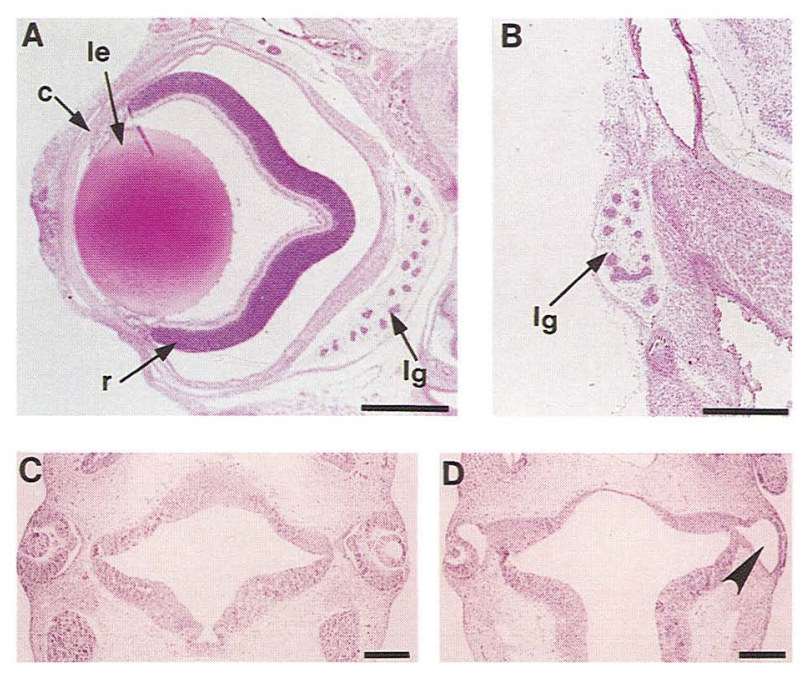
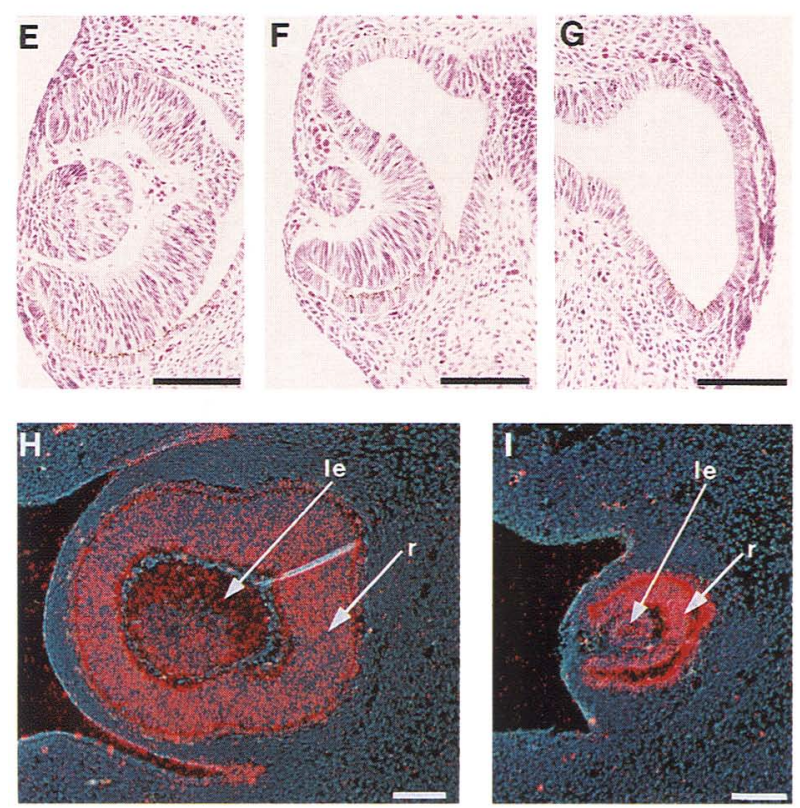


\section{$B M P-7$ is required for normal skeletal patterning}

In the $b m p-7^{m 1} / b m p-7^{m 1}$ mice, skeletal abnormalities were identified in discrete areas: the rib cage, the skull, and the hindlimbs. In the rib cage, the phenotype varied; however, all of the mutants had some or all of the following features: asymmetric pairing of ribs, fusion of ribs, less than seven pairs of attached ribs, reduction of one or both of the most posterior pair of ribs, and malformation of the xiphoid process (Fig. 6A,B). In the skull, three abnormalities were consistently observed: (1) smaller basosphenoid bones with a cavity in the center; (2) fusion of the basosphenoid with the occipital bone through a piece of cartilaginous tissue; and (3) marked reduction of the pterygoid bones (Fig. 6C,D). Despite the high level of expression of BMP-7 in the axial skeleton (Lyons et al. 1995), a consistent defect in the patterning of the axial skeleton was not observed.

Most of the BMP-7-deficient mice ( $82 \%$ ) could be identified phenotypically because of the presence of an extra digit in the hindlimbs (polydactyly). A few animals $(12 \%)$ also exhibited polydactyly in the forelimbs. The extra digit was always a preaxial duplication and had the morphology of digit II, III, IV, or V (Fig. 6F).
In developing mouse limb buds $B m p-7$ is expressed in the entire limb field at $9.5 \mathrm{dpc}$, including the limb mesenchyme and the overlying ectoderm (Lyons et al. 1995; data not shown). At $10.5 \mathrm{dpc}$, when the apical ectodermal ridge (AER) becomes distinct in the developing mouse limb, Bmp-7 transcripts are found mostly in the AER, although they are also present at a lower level in the anterior and posterior mesenchyme underlying the AER (data not shown). At $11.0 \mathrm{dpc} B m p-7$ expression is prominent in the AER but is also expressed weakly in the underlying mesenchyme (Fig. 7A). At $11.5 \mathrm{dpc}$, expression is down-regulated in epithelial cells of the AER and appears in underlying mesenchymal cells of the progress zone (data not shown). At 12.5 and $14.5 \mathrm{dpc}$ Bmp-7 was expressed in interdigital mesenchymal cells and in the subdermic layer of the limb bud, outlining future digits (Fig. 7B,C).

To identify changes in gene expression patterns that might represent early determinants of polydactyly, two molecular markers, Sonic HedgeHog (Shh) (Riddle et al. 1993) and Hoxd-13 (Dolle et al. 1991), were examined in the developing limb buds of $11.0-\mathrm{dpc}$ wild-type and bmp$7^{m 1} / b m p-7^{m 1}$ embryos. The partial mirror image duplication observed in $b m p-7^{m 1} / b m p-7^{m 1}$ limbs might be
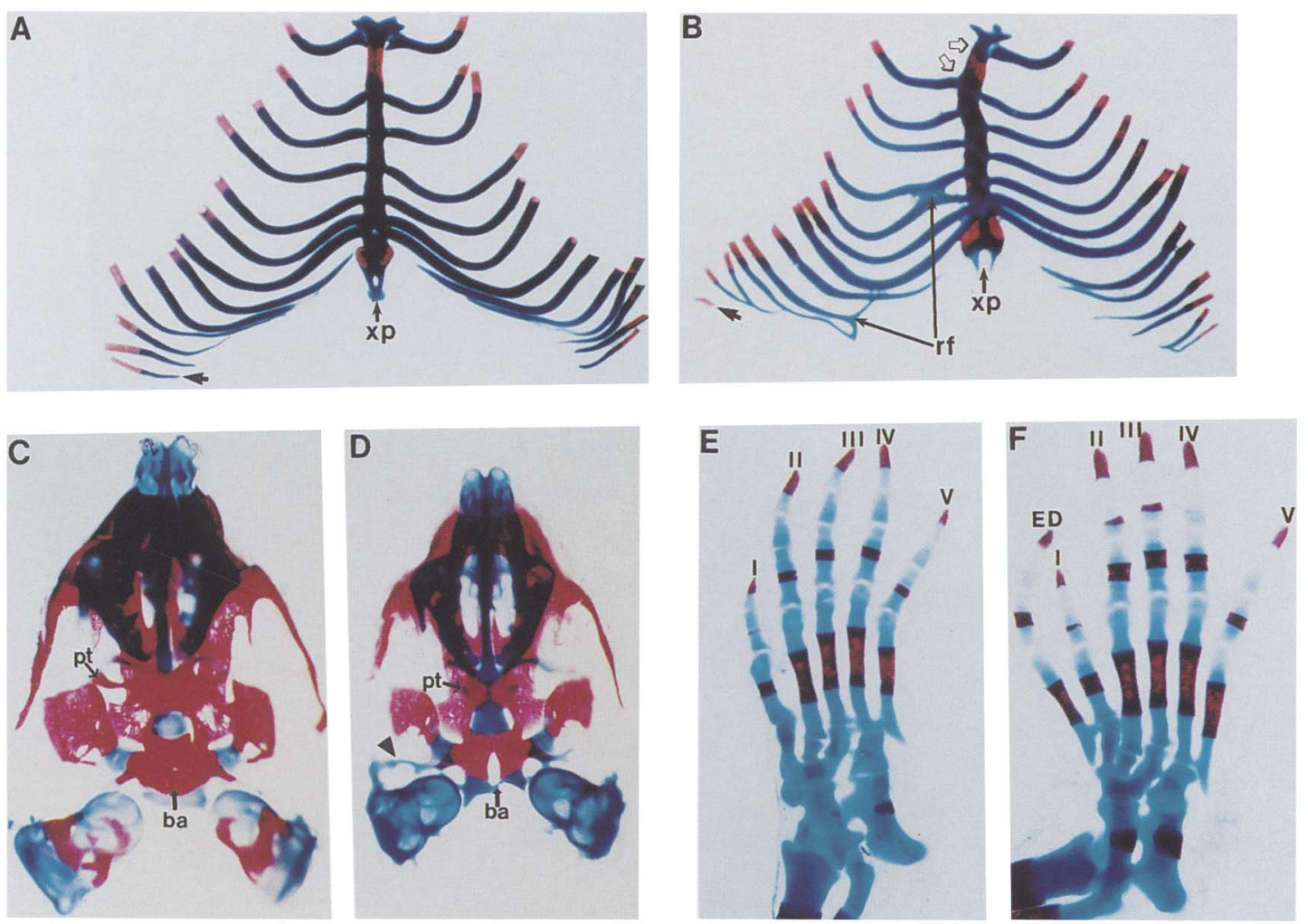

Figure 6. Skeletal phenotype of BMP-7-deficient mice. $(A, B)$ Skeletal preparations of rib cages of newborn wild-type $(A)$ and mutant $(B)$ mice. Several defects in the mutant rib cage are indicated: misalignment of the rib pairs on the sternum (open arrows); rib fusion $(\mathrm{rf})$; modification of the shape of the xiphoid process (xp); size reduction of rib 13 (short, solid arrow in $B) .(C, D)$ Ventral view of skeleton of skulls of newborn mice after the parietal bones and frontal bones were removed. The three defects in the mutant skull are indicated: presence of a cavity in the basosphenoid bone (ba); fusion between right alisphenoid and inner ear (arrowhead in $D$ ); and reduction in the sizes of the pterygoid bones $(\mathrm{pt}) .(E, F)$ Skeletal preparation of the right hindlimb of wild-type $(E)$ and mutant $(F)$ newborn mice. Digits are numbered from anterior to posterior; an extra digit present in the mutant is indicated (ED). 

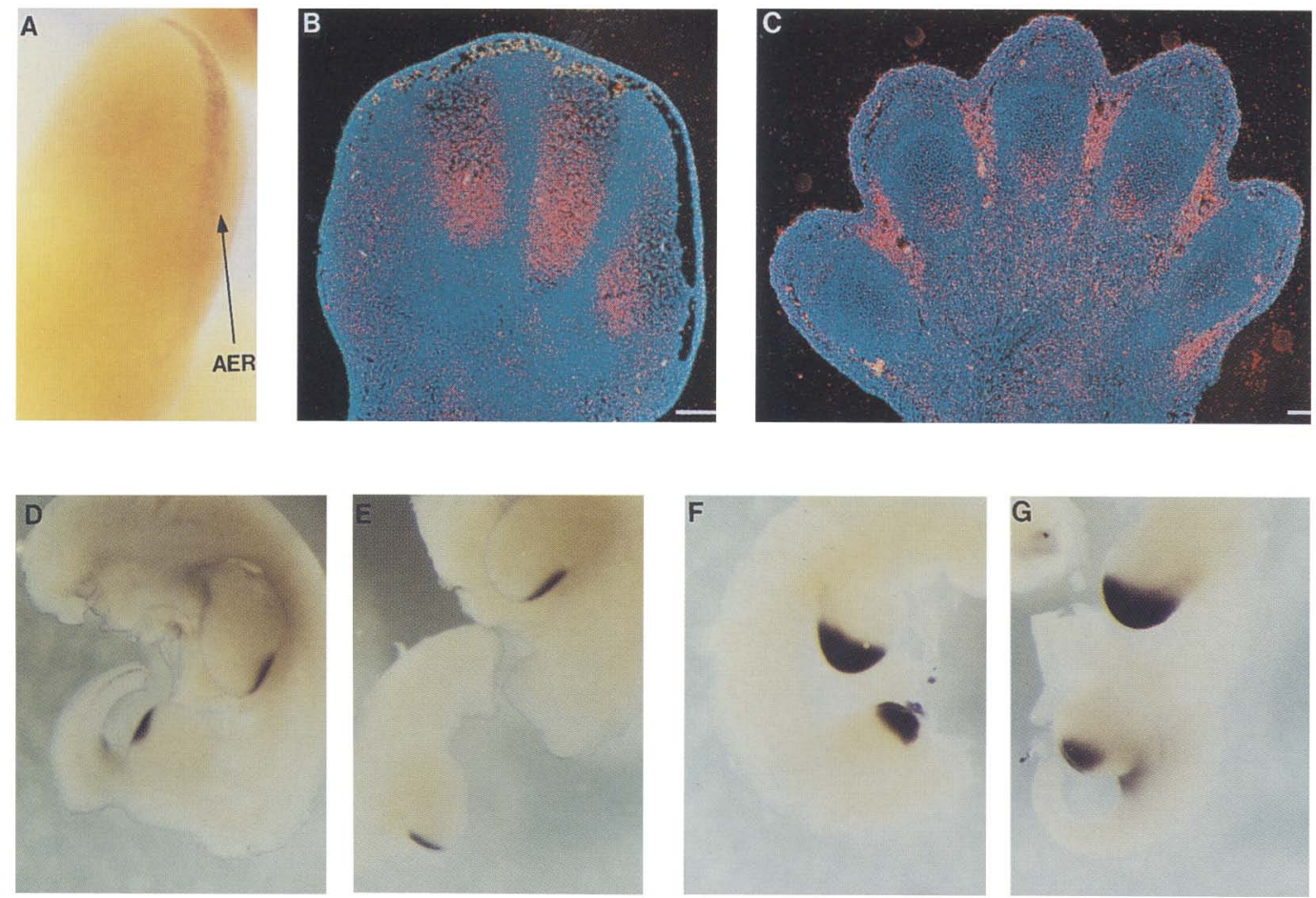

Figure 7. Expression of Bmp-7, Shh, and Hoxd-13 during limb development of wild-type and BMP-7-deficient mice. (A) Whole-mount in situ hybridization of $B m p-7$ during limb development. At $11.0 \mathrm{dpc}$, the expression of $B m p-7$ is predominant in the AER. $(B, C)$ Section in situ hybridization of $B m p-7$ in $12.5 \mathrm{dpc}(B)$ and $14.5 \mathrm{dpc}(C)$ hindlimbs. At both 12.5 and $14.5 \mathrm{dpc} B \mathrm{mp}-7$ is expressed in the interdigital mesenchyme that outlines the future digits. $(D, E)$ Shh expression in the developing limb buds of 11.0 -dpc wild-type $(D)$ and mutant $(E)$ embryos. There is no difference between the wild type and the mutant in both the forelimb and the hindlimb. $(F, G) H o x d-13$ expression in the developing limb buds of 11.0 -dpc wild-type $(F)$ and mutant $(G)$ embryos. In the $b m p-7^{m 1} / b m p-7^{m 1}$ limb, Hoxd-13 expression is restricted to a smaller area of the posterior part of the limb bud compared with the wild-type control. The lower level of Hoxd-13 was observed consistently. Hoxd-13 expression in the forelimb between the wild-type and the mutant embryos is similar. Bars, $100 \mu \mathrm{m}$.

related to altered expression of Shh or Hoxd-13. Mutant and wild-type embryos were cut midsagitally, and the embryo halves were probed separately for Shh and Hoxd13 expression. Shh expression was identical in wild-type and mutant limbs (Fig. 6D,E); in contrast, Hoxd-13, which is expressed in the posterior and distal part of the wild-type hindlimbs, was restricted to a smaller region in the posterior part of the mutant hindlimbs. Hoxd-13 expression was weaker overall in the mutant hindlimbs. In the forelimb of mutant embryos Hoxd-13 expression was slightly weaker.

\section{Discussion}

We have generated BMP-7-deficient mice by deleting the sequence coding for the mature domain of the protein. This allele is recessive because heterozygotes carrying the $b m p-7^{m 1}$ allele are normal, whereas $b m p-7^{m 1} / b m p$ $7^{\mathrm{m} 1}$ mice exhibit a multitude of defects in nephrogenesis, ocular development, and skeletogenesis.

\section{BMP-7 and kidney development}

During vertebrate development the metanephric mesen- chyme undergoes an epithelial transformation to form the glomerulus and the tubules of the nephrons. This nephrogenic process begins at $11.5 \mathrm{dpc}$ with mesenchymal condensation and is initiated by signals coming from the ureteric bud (Saxen 1987). Classic coculture experiments have established that inductive signals coming from the ureteric bud could be short-range diffusible factors, such as growth factors (Gruenwald 1937; Grobstein 1957; Saxen et al. 1976). Recently, specific factors required for glomerulus formation, such as Wnt-4 (Stark et al. 1994), have begun to be identified by genetic means. In Wnt-4-deficient mice, mesenchymal cells condense around the ureteric buds and express molecular markers, such as Pax-2 and WT1, until at least $14.5 \mathrm{dpc}$, suggesting that the absence of Wnt-4 does not affect the early stage of glomerulus formation. Therefore, different signals are involved in the early steps of nephrogenesis.

The observations reported in this paper suggest that BMP-7 is an early inducer of nephrogenesis. Bmp-7 is expressed in the ureteric bud at the appropriate time of development. Moreover, in the absence of BMP-7 only incomplete mesenchymal condensations are identified in the kidney at $12.5 \mathrm{dpc}$. In the absence of BMP-7 the metanephric mesenchymal cells died before $14.5 \mathrm{dpc}$, a 
phenomenon that is also observed when the metanephric mesenchyme is cultured in the absence of proper inductive tissues (Saxen 1987). The few mesenchymal condensations observed in $b m p-7^{m 1} / b m p-7^{m 1}$ mice at $12.5 \mathrm{dpc}$ are probably responsible for the handful of glomeruli identified in the kidneys of neonatal mutant mice. These might be explained by passive placental transfer of maternal BMP-7, a phenomenon that has been documented for another member of the TGF- $\beta$ superfamily, TGF- $\beta 1$ (Letterio et al. 1994). Because nephrogenesis proceeds normally until $12.0 \mathrm{dpc}$ in $b m p-7^{m 1} / b m p-7^{m 1}$ mice, other inductive signals must be acting before to this time. Our findings imply that BMP-7 regulates target genes in metanephric mesenchymal cells that are critical for nephrogenesis. These genes might be involved directly in the differentiation/proliferation of metanephric mesenchyme or, alternatively, genes whose products are necessary for cell survival might be the targets of BMP-7.

\section{BMP-7 and eye development}

Lens formation is the result of reciprocal inductive interaction between the optic vesicle and the surface ectoderm (Spemann 1901 1912). Genetic evidence has demonstrated that the optic vesicle is required for lens formation in mice (Webster et al. 1984). In mice, this reciprocal interaction leads to the formation of the lens vesicle from the surface ectoderm at $\sim 10.5 \mathrm{dpc}$ (Pei and Rhodin 1970; Kaufman 1992). In about $35 \%$ of bmp- $7^{m 1} /$ $b m p-7^{m 1}$ embryos, interaction between the optic vesicle and the surface ectoderm did not occur properly, resulting in the uni- or bilateral absence of lens formation in these animals. The expression of Bmp-7 during eye development suggests that BMP-7 is involved directly in lens formation. That is, it could be one of the factors released by the optic vesicle during lens induction. The importance of BMP-7 during eye development has also been suggested by in vitro culture experiments showing that anti-BMP-7 antibodies can block lens formation in cultured rat embryos $\{K$. Sampath and M. Solursh, pers. comm.). However, $86 \%$ of the $b m p-7^{m 1} / b m p-7^{m 1} \mathrm{em}-$ bryos did develop lens (or lenses), indicating that genes segregating in the $\mathrm{F}_{2}$ animals can suppress this aspect of the BMP-7-deficient phenotype.

\section{BMP-7 and skeletal development}

BMP-7-deficient mice have defects in skeletal development that are restricted to a limited subset of skeletal elements. These skeletal abnormalities were absent in all of the heterozygous animals studied and were never observed as a group in any of the mutant mice strains generated with this ES cell line. This strongly suggests that the mutation in the $B m p-7$ locus is responsible for these defects.

The most penetrant skeletal phenotype in $b m p-7^{m 1} /$ $b m p-7^{m 1}$ mice was the presence of a sixth preaxial digit in both hindlimbs. The restriction of polydactyly to the hindlimbs illustrates the nonequivalence of forelimb and hindlimb development. Polydactyly is one of the most frequent abnormalities observed in humans (Mellin 1963; Tentamy and McKusick 1978) and has been documented repeatedly in mice (Mendelsohn et al. 1994; Wurst et al. 1994; Fawcett et al. 1995). At least two hypotheses could explain the presence of an extra digit in BMP-7-deficient mice. One possibility would be that BMP-7 prevents excessive proliferation of cells in the progress zone below the AER or later in the interdigital mesenchyme. In the absence of BMP-7, another digit would form in the anterior part of the limb because of the condensation of excessive mesenchyme. This would imply that BMP-7 controls survival of mesenchymal cells in the limb; however, we did not observe any significant difference in the number of cells undergoing apoptosis in the limb mesenchyme between wild-type and mutant embryos (data not shown). A second hypothesis would be that the absence of BMP-7 affects the pattern of the expression of genes controlling the anteroposterior axis in digit formation. We analyzed the expression of Shh and Hoxd-13 in BMP-7-deficient mice and normal littermates at $11.0 \mathrm{dpc}$ and could show that Hoxd-13 expression was weaker and restricted to its more posterior part in the mutants. These results suggest that BMP-7 inhibits hindlimb growth and that abnormal expression of Hoxd-13 in BMP-7-deficient mice could lead to the formation of an extra (preaxial) digit. The expression of another $B m p, B m p-2$, has also been shown to be closely linked to Hoxd-13 expression during limb bud development, and it has been suggested that BMP-2 could activate Hoxd-13 during limb development (Francis et al. 1994). Interestingly, BMP-2 inhibits limb growth in chick (Niswander and Martin 1993).

In summary, the generation of BMP-7-deficient mice has provided additional evidence that this family of growth factors regulate many morphogenetic processes including, but not limited to, skeletal development. In particular, our experiments demonstrate that BMP-7 acts as an early inducer of glomeruli formation and that it is required for skeletal patterning and lens formation. Our results not only demonstrate that BMP-7 is involved in the differentiation of several organs during development but also raise the hypothesis that mutations in the Bmp-7 gene itself or in the genetic pathway could be responsible for several human genetic diseases in which glomerulus formation is impaired.

\section{Materials and methods}

BMP-7 targeting vector and generation of chimeras

To generate the targeting vector for positive-negative selection, a mouse 129 /SvEv genomic library was screened, using a PCRamplified 294-bp cDNA fragment from the 3 '-untranslated region (from nucleotide 1397 to 1690) of the mouse Bmp-7 (OP-1) cDNA (Ozkaynak et al. 1991). Overlapping phages covering the three most 3' exons were isolated and mapped. A replacementtype targeting vector, $\mathrm{pBMP} 7 \mathrm{~T}$, was constructed. The vector contains a $3.2-\mathrm{kb}$ homology $5^{\prime}$ to exon 6 and a $2.9-\mathrm{kb}$ homology 3 ' to exon 7 (Fig. 1). The PGK-hprt (where PGK is the phosphoglycerate kinase 1 promoter) expression cassette was cloned 
between the two homologous arms, and a $M C 1-t k$ expression cassette was cloned into the polylinker site of the plasmid backbone, which is outside the homologous regions. The vector was designed so that both exons 6 and 7 would be deleted after correct targeting. The 5 '-flanking probe was an 800 -bp EcoRI$B g I I I$ fragment $3.0-\mathrm{kb}$ upstream of the $5^{\prime}$ homologous arm, and the 3 '-flanking probe was a 700-bp EcoRI-HindIII fragment just downstream of the $3^{\prime}$ homologous region. The correct targeting event converts a $13.0-\mathrm{kb} \mathrm{XbaI}$ wild-type fragment, into a 10.9 $\mathrm{kb} \mathrm{XbaI} \mathrm{fragment,} \mathrm{and} \mathrm{a} \mathrm{9.2-kb} \mathrm{HindIII} \mathrm{wild-type} \mathrm{fragment} \mathrm{into}$ a $5.6-\mathrm{kb}$ HindIII fragment, which can be revealed by Southern blot hybridization using the 5 ' - and 3 '-flanking probes, respectively (Fig. 1).

The culture and transfection of ES cells was performed exactly as described previously (Ramirez-Solis et al. 1993). Briefly, AB2.1 ES cells were transfected with $25 \mu \mathrm{g}$ of SalI-linearized pBMP7T per $10^{7}$ cells using a Bio-Rad gene pulser and grown under double selection as described. The targeted clones were identified by Southern blot hybridization with genomic DNA from each individual clone. The targeted ES cells were then injected into C57BL/ 6 blastocysts (Bradley 1987), which were then transferred into the uterus of pseudopregnant females. Resulting male chimeras were mated to $\mathrm{C} 57 \mathrm{BL} / 6$ females, and heterozygous offspring identified by Southern blot hybridization. The heterozygotes $\left(F_{1}\right)$ were then interbred to generate homozygous BMP-7-deficient mice (or embryos) $\left(\mathrm{F}_{2}\right)$.

\section{Southern blot analysis}

DNA isolation from double-resistant ES cells or mouse tails and Southern blot analysis were performed as described previously (Matzuk et al. 1992). DNA was digested with either XbaI or HindIII and electrophoresed in a $0.7 \%$ agarose gel. DNA was then transferred onto Hybond- $\mathrm{N}^{+}$nylon membranes (Amersham International, Inc., Amersham, UK), and standard Southern hybridization procedures were followed.

\section{Northern blot hybridization}

Total RNA samples were prepared using the guanidinium thiocyanate-CsCl gradient method as described, and Northern blot hybridization was performed as described (Sambrook et al. 1989) with minor modification. Briefly, total RNA samples were fractionated on a formaldehyde gel, and the nucleic acids were transferred onto a Hybond- $\mathrm{N}^{+}$nylon membrane. The hybridization procedure was the same as that for Southern blot hybridization described above.

\section{Histological analysis of embryos}

Embryos of various stages of development were dissected free of the uterine muscle and decidua, and the yolk sacs were saved for DNA analysis. Histology procedures were as described (Kaufman 1992), with minor modifications. The embryos were fixed overnight in $4 \%$ paraformaldehyde solution and transferred to $70 \%$ ethanol. The fixed embryos were dehydrated through graded series of ethanol. Specimens were embedded in either paraffin or plastic for sectioning. Sections were stained with hematoxylin and eosin as described by Culling et al. (1985), except those for kidney histology, which were stained by the periodic acid Schiff (PAS) staining according to Spicer et al. (1967).

Section in situ hybridization and whole-mount in situ hybridization

The probes used to survey the expression of $B m p-7$, Laminin $A$,
WT1, Wnt-4, and Pax-2 were described previously (Dressler et al. 1990; Klein et al. 1990; Ozkaynak et al. 1991; Armstrong et al. 1992; Stark et al. 1994). cDNA probes for WT1, Pax-2, and Laminin A were obtained from Drs. J. Pelletier (McGill University, Montreal, Canada), G. Dressler (University of Michigan, Ann Arbor), and Y. Yamada (NIH, Bethesda, MD), respectively. cDNA probes for Bmp-7 and Wnt-4 were amplified by RT-PCR according to published information, cloned into pBSKS $(-)$ (Stratagene, La Jolla, CA), and sequenced. For each probe, both sense and antisense riboprobes were prepared using either $\mathrm{T} 3$ or T7 RNA polymerase, and both probes were used in each set of experiments. Section in situ hybridization procedures were as described (Sundin et al. 1990), with the following modification. Sections of $8 \mu \mathrm{m}$ were mounted onto polylysine-treated slides. The hybridization and posthybridization washes were performed as described (Wilkinson 1992). Briefly, the sections were hybridized overnight at $50^{\circ} \mathrm{C}$. The stringency washes were at $64^{\circ} \mathrm{C}$. Exposure times were $10-16$ days. Autoradiography, Hoechst 33258 staining, and photography were performed as described (Sundin et al. 1990), as well as whole-mount in situ hybridization procedures (Takata et al. 1994).

\section{Programmed cell death analysis}

The analysis was carried out according to the published TUNEL procedure (Gavrieli et al. 1992). Sections of mouse embryos were prepared as described for in situ hybridization.

\section{Skeleton preparation}

Skeletons were prepared as described (Kochhar 1973). Neonates were sacrificed, skinned, eviscerated, and fixed in $95 \%$ ethanol. Nonskeletal tissues were digested with $2 \%$ potassium hydroxide. Cartilaginous tissues were stained by alcian blue 8GX, and ossified tissues were stained by alizarin red S.

\section{Acknowledgments}

We thank Drs. D. Duboule, G. Eichele (G.E.), M. Finegold, A. McMahon, G. Pelletier, H. Opperman, P. Overbeek, K. Sampath, L. Striker, R. d'Souza, Y. Yamada, and H. Zhang for cDNA probes and for critical help and advice during the course of this study. G.L. is particularly grateful to Dr. P. Ducy for her invaluable help in the initial analysis of the mice, in generating the figures, and for her critical reading of the manuscript. We also thank X. Guo for technical support. This work was supported by National Institutes of Health (NIH) grant AR-41059, Basic Research Award IFY 92-0871 from the March of Dimes Foundation, and a grant from the Roussel Scientific Institute to G.K. C.H. was supported by NIH grant HD20209, awarded to G.E. for the early part of this work. A.B. is a Howard Hughes Medical Institute Investigator; research in his laboratory is also supported by the National Institutes of Health.

The publication costs of this article were defrayed in part by payment of page charges. This article must therefore be hereby marked "advertisement" in accordance with 18 USC section 1734 solely to indicate this fact.

\section{References}

Armstrong, J.F., K. Pritchard-Jones, W.A. Bickmore, N.D. Hastie, and J.B.L. Bard. 1992. The expression of the Wilms' tumor gene, WT 1, in the developing mammalian embryo. Mech. Dev. 40: 85-97.

Bradley, A.. 1987. Production and analysis of chimeric mice. In 
Teratocarcinomas and embryonic stem cells: A practical approach (ed. E.J. Robertson), pp. 113-151. IRL Press, Oxford, UK

Call, K.M., T. Glaser, C.Y. Ito, A.J. Buckler, J. Pelletier, D.A. Haber, E.A. Rose, A. Kral, H. Yeger, W.H. Lewis, C. Jones, and D.E. Housman. 1990. Isolation and characterization of a zinc finger polypeptide gene at the human chromosome 11 Wilms' tumor locus. Cell 60: 509-520.

Culling, C.F.A., R.T. Allison, and W.T. Barr. 1985. Cellular pathology technique, 4th ed. Butterworths, London, UK.

Dale, L., G. Howes, B.M. Price, and J.C. Smith. 1992. Bone morphogenetic protein 4: A ventralizing factor in early Xenopus development. Development 115: 573-585.

Dollé, P., J.-C. Izpisua-Belmonte, C. Tickle, J. Brown, and D. Duboule. 1991. The Hox 4.8 gene is localized at the $5^{\prime}$ extremity of the Hox 4 complex and is expressed in the most posterior parts of the body during development. Mech. Dev. 36: 3-14.

Dressler, G.R., U. Deutsch, K. Chowdhury, H.O. Nornes, and P. Gruss. 1990. Pax 2, a new murine paired-box-containing gene and its expression in the developing excretory system. Development 109: 787-795.

Dressler, G.R., J.E. Wilkinson, V.W. Rothenpieler, L.T. Patterson, L. Williams-Simons, and H. Westphal. 1993. Deregulation of Pax-2 expression in transgenic mice generates severe kidney abnormalities. Nature 362: 65-67.

Fawcett, D., P. Pasceri, R. Fraser, M. Colbert, I. Rossant, and V. Giguere. 1995. Post axial polydactyly in forelimbs of CRABP-II mutant mice. Development 121: 671-679.

Ferguson, E.L. and K.V. Anderson. 1992. Decapentaplegic acts as a morphogen to organize dorsal-ventral pattern in the Drosophila embryo. Cell 71: 451-461.

Francis, P.H., M.K. Richardson, P.M. Brickell, and C. Tickle. 1994. Bone morphogenetic proteins and a signalling pathway that controls patterning in the developing chick limb. Development 120: 209-218.

Gavrieli, Y., Y. Sherman, and S.A. Ben-Sasson. 1992. Identification of programmed cell death in situ via specific labeling of nuclear DNA fragmentation. J. Cell Biol. 119: 493-501.

Grindley, J.C., D.R. Davidson, and R.E. Hill. 1995. The role of Pax-6 in eye and nasal development. Development 121: 1433-142.

Grobstein, C. 1953. Morphogenetic interaction between embryonic mouse tissues separated by a membrane filter. Nature 172: 869-871.

- Inductive interaction in the development of the mouse metanephros. I. Exp. Zool. 130: 319-340.

1957. Some transmission characteristics of the tubuleinducing influence on mouse metanephrogenic mesenchyme. Exp. Cell Res. 13: 575-587.

Gruenwald, P. 1937. Zur Entwicklungsmechanik der Urogenital-systems beim Huhn. Wilhelm Roux's Arch. Dev. Biol. 136: $786-813$.

Halder, G., P. Callaerts, and W.J. Gehring. 1995. Induction of ectopic eyes by targeted expression of the eyeless gene in Drosophila. Science 267: 1788-1792.

Hogan, B.L.M., E.M.A. Hirst, G. Horsburgh and C.M. Hetherington. 1988. Small eye (Sey): A mouse model for the genetic analysis of craniofacial abnormalities. Development. (Suppl.)103: 115-119.

Kaufman. M.H. 1992. In The atlas of mouse development (ed. M.H. Kaufman), pp. 389-407. Academic Press, San Diego, CA.

Kingsley, D.M., A.E. Bland, J.M. Grubber, P.C. Marker, L.B. Russell, N.G. Copeland, and N.A. Jenkins. 1992. The mouse short ear skeletal morphogenesis locus is associated with defects in a bone morphogenetic member of the TGF- $\beta$ superfamily. Cell 71: 399-410.

Klein, G., M Ekblom, L. Fecker, R. Timpl, and P. Ekblom. 1990. Differential expression of laminin A and $\mathrm{B}$ chains during development of embryonic mouse organs. Development 110: $823-837$.

Kochhar, D.M. 1973. Limb development in mouse embryos. I. Analysis of teratogenic effects of retinoic acid. Teratology 7: 289-298.

Koseki, C., D. Herzlinger, and Q. Al-Awqati. 1992. Apoptosis in metanephric development. J. Cell Biol. 119: 1327-1333.

Kreidberg, I.A., H. Sariola, J.M. Loring, M. Maeda, J. Pelletier, D. Housman, and R. Jaenisch. 1993. WT-1 is required for early kidney development. Cell 74: 679-691.

Letterio, J.J., A.G. Geiser, A.B. Kulkarni, N.S. Roche, M.B. Sporn, and A.B. Roberts. 1994. Maternal rescue of transforming growth factor- $\beta 1$ null mice. Science 264: 1936-1938.

Lyons, K.M., R.W. Pelton, and B.L.M. Hogan. 1989. Patterns of expression of murine Vgr-1 and BMP-2a RNA suggest that transforming growth factor- $\beta$-like genes coordinately regulate aspects of embryonic development. Genes \& Dev. 3: $1657-1668$.

-1990. Organogenesis and pattern formation in the mouse: RNA distribution patterns suggest a role for bone morphogenetic protein-2A (BMP-2A). Development 109: $833-844$.

Lyons, K.M., B.L.M. Hogan, and E.J. Robertson. 1995. Colocalization of $B m p-7$ and $B m p-2$ RNAs suggests that these factors cooperatively mediate tissue interactions during murine development. Mech. Dev, 50: 71-83.

Matzuk, M.M., M.J. Finegold, J.-G.J. Su, A.J.W. Hsueh, and A. Bradley. 1992. $\alpha$-Inhibin is a tumour-suppresser gene with gonadal specificity in mice. Nature 360: 313-319.

Mellin, G.W. 1963. The frequency of birth defects. In Birth defects (ed. M. Fishbein), pp. 11-17. J.B Lippencott. Philadelphia, PA.

Mendelsohn, C., M. Mark, P. Dollé, A. Dierich, M.P. Gaub, A. Krust, C. Lampron, and P. Chambon. 1994. Retinoic acid receptor beta 2 (RAR beta 2 ) null mutant mice appear normal. Dev. Biol. 166: 246-258.

Niswander, L. and G.R. Martin. 1993. FGF-4 and BMP-2 have opposite effects on limb growth. Nature 361: 68-71.

Ozkaynak, E., D.C. Rueger, E.A. Drier, C. Corbett, R.J. Ridge, T.K. Sampath, and H. Oppermann. 1990. OP-1 cDNA encodes an osteogenic protein in the TGF-beta family. EMBO J. 9: 2085-2093.

Ozkaynak, E., P.N.J. Schnegelsberg, and H. Oppermann. 1991. Murine osteogenic protein (OP-1): High level of mRNA in the kidney. Biochem. Biophys. Res. Commun. 179: 116123.

Parr, B.A. and A.P. McMahon. 1994. Wnt genes and vertebrate development. Curr. Opin. Genet. Dev. 4: 523-528.

Pei, Y.F. and J.A.G. Rhodin. 1970. The prenatal development of the mouse eye. Anat. Rec. 168: 105-126.

Ramirez-Solis, R., A. Davis, and A. Bradley. 1993. Gene targeting in embryonic stem cells. Methods Enzymol. 225: 855878.

Riddle, R.D., R.L. Johnson, E. Laufer, and C. Tabin. 1993. Sonic hedgehog mediates the polarizing activity of the ZPA. Cell 75: 1401-1416.

Sambrook, J., E.F. Fritsch, and T. Maniatis. 1989. Molecular cloning: A laboratory manual Cold Spring Harbor Laboratory Press, Cold Spring Harbor, New York.

Sampath, T.K. and A.H. Reddi. 1981. Dissociative extraction and reconstitution of extracellular matrix components involved in local bone differentiation. Proc. Natl. Acad. Sci. 
Luo et al.

78: 7599-7603.

Saxen, L.. 1987. Organogenesis of the kidney. Cambridge University Press, Cambridge, UK.

Saxen, L., E. Lehtonen, M. Karkinen-Jaeaekelaeinen, S. Nordling, and J. Wartiovaara. 1976. Are morphogenetic tissue interactions mediated by transmissible signal substances or through cell contacts? Nature 259: 662-663.

Spemann, H.. 1901. Ueber Korrelationen in der Entwicklung des Auges. Verh. Anat. Ges. 15: 61-79.

- 1912. Zur Entwicklung des Wirbeltierauges. Zool. lahrb. Abt. Allg. Zool. Physiol. Tiere 32: 1-98.

Spicer, S.S., R.G. Horn, and T.J. Leppi. 1967. Histochemistry of connective tissue mucopolysaccharides. The connective tissues. Int. Acad. Pathol. 7: 251-303.

Stark, K., S. Vainio, G. Vassileva, and A.P. McMahon. 1994. Epithelial transformation of metanephric mesenchyme in the developing kidney regulated by Wnt-4. Nature 372: 679683.

Storm, E.E., T.V. Huynh, N.G. Copeland, N.A. Jenkins, D.M. Kingsley, and S.-L. Lee. 1994. Limb alterations in brachypodism mice due to mutations in a new member of the TGF-b superfamily. Nature 368: 639-643.

Sundin, O.H., H.G. Busse, M.B. Rogers, L.J. Gudas, and G. Eichele. 1990. Region-specific expression in early chick and mouse embryo of Ghox-lab and Hox 1.6, vertebrate homeobox-containing genes related to Drosophila labial. Development 108: 47-58.

Takada S., K.L. Stark, M.J. Shea, G. Vassileva, J.A. McMahon, and A.P. McMahon. 1994. Wnt-3a regulates somite and tailbud formation in the mouse embryo. Genes \& Dev. 8: 174189.

Tentamy, S., and V. McKusick. 1978. The genetics of hand malformations, Vol. XIV. Liss, New York.

Urist, M.R. 1965. Bone: Formation by autoinduction. Science 150: $893-899$.

Vukicevic, S., V. Latin, P. Chen, R. Batorsky, A.H. Reddi, and T.K. Sampath. 1994. Localization of osteogenic protein-1 (bone morphogenetic protein-7) during human embryonic development: High affinity to basement membranes. Biochem. Biophys. Res. Comm. 198: 693-700.

Webster, E.H.J., A.F. Silver, and N.I. Gonsalves. 1984. The extracellular matrix between the optic vesicle and the presumptive lens during lens morphogenesis in an anophthalmic strain of mice. Dev. Biol. 103: 142-150.

Wilkinson, D.G.. 1992. In situ hybridization. In In situ hybridization: A practical approach (ed. D.G. Wilkinson), pp. 257263. IRL Press, Oxford, UK.

Winnier, G., M. Blessing, P.A. Labosky, and B.L.M. Hogan. 1995. Bone morphogenetic protein-4 is required for mesoderm formation and patterning in the mouse. Genes \& Dev. 9: 2105-2116.

Wozney, J.M., V. Rosen, A.J. Celeste, L.M. Mitsock, M.J. Whitters, R.W. Kriz, R.M. Hewick, and E.A. Wang. 1988. Novel regulators of bone formation: Molecular clones and activities. Science 242: 1528-1534.

Wurst, W., A.B. Auerbach, and A.L. Joyner. 1994. Multiple developmental defects in Engrailed-1 mutant mice: An early mid-hindbrain deletion and patterning defects in forelimbs and sternum. Development 120: 2065-2075. 


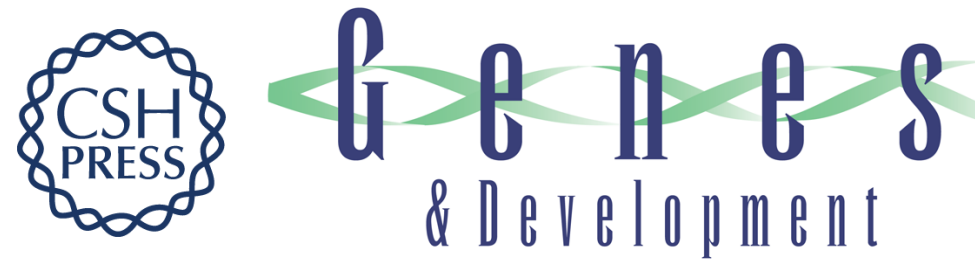

\section{BMP-7 is an inducer of nephrogenesis, and is also required for eye development and skeletal patterning.}

G Luo, C Hofmann, A L Bronckers, et al.

Genes Dev. 1995, 9:

Access the most recent version at doi:10.1101/gad.9.22.2808

References This article cites 50 articles, 20 of which can be accessed free at:

http://genesdev.cshlp.org/content/9/22/2808.full.html\#ref-list-1

License

Email Alerting

Service

Receive free email alerts when new articles cite this article - sign up in the box at the top right corner of the article or click here.

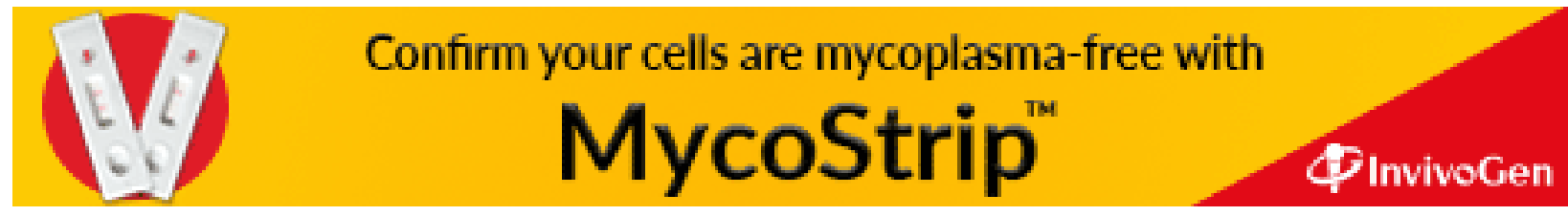

